\title{
An Investigation of Attention-Seeking Behavior through Social Media Post Framing
}

\author{
By Francine Edwards*
}

\begin{abstract}
The rise in the use of social networking sites (SNSs) and the very nature of a medium which provides users with a platform to create both a favorable image for ones' self and the relationships that are perceived as valuable is worthy of investigating as these relationships are becoming as complimentary or as necessary as interpersonal or face-to-face contact. Social networking sites are a means of conveying ideas, dissent, comradery, and emotions all crafted by a user with the intent of emoting a specific response from their followers or friends. The current research suggests that SNS users seek various types of feedback as a result of the communication created by them in the form of social media posts. For the purpose of this research Facebook was used to a) collect data about social media usage b) analyze predictors of social behavior and c) look at the connection between attention-seeking behavior and social media.
\end{abstract}

Keywords: attention-seeking, affirmation, feedback, social media, communication

\section{Introduction}

Narcissism, defining our self-worth, and validation has always been a part of human nature; however social media has created digital and seemingly endless means of having our basic needs for acceptance met. Attention addiction has increased relevance in today's social media environment. While most social media users do not display narcissistic tendencies, what can be found on social media are self-promoting or personal platform displays; and intentional displays designed to emote attention with words. While the field of media psychology is emerging, the value of understanding human behavior at the intersection of media technologies is that this field bridges a gap by helping us to have a better understanding of the implications of media usage (Rutledge, nd).

Previous research on social media use has focused on two paradigms: one of deficiency (in which a user compensates for unhealthy interpersonal interaction with others) and the second, a global use paradigm (online behavior/usage is equivalent to interpersonal interaction) (Tsao, 1996). Connectivity becomes a central facet of social media usage in that there are perceived reasons as to why one may feel more disconnected with limited online connectivity as opposed to face-to-face interaction and feelings of loneliness and a lack of connectivity.

Parasocial interaction in the online environment was perceived as negative in early research. The effects of this new medium were described as having the potential to ruin lives; others argued that real lives and real life activity would

\footnotetext{
* Associate Professor, Chair - Department of Mass Communications, Interim Dean - College of Arts Humanities and Social Sciences, Delaware State University, Mass Communications Department, USA.
} 
be neglected and one study theorized that online activity garnered negative reputations (Freberg, et al., 2010). Kraut et al., (1998), study exemplified Tsao's deficiency paradigm, in that the data supported the notion that users were foregoing healthy interpersonal/face-to-face relationships for constructed online relationships.

Online experience has been enriched (and in the eyes of some complicated) by the advent social networking sites (SNSs). According to Boyd \& Ellison (2008) social networking sites provide a rich environment for analyzing the psychological impact of online interaction and emotional wellbeing. The mere design of these sites allows for communication within a bounded system in which the user controls who they share and connect with. It is also a system in which sharing can traverse across connections made by other users of the site (Boyd \& Ellison, 2008, p. 211). One of the most popular of the current SNSs is Facebook, which has seen a distinct change in the demographic of users from the initial college audience to the users in their $30 \mathrm{~s}$ and 40s. To date, the majority of the research in which Facebook has been the subject has focused on privacy. There is a growing body of research which focuses on the decline of happiness, issues of authenticity, and narcissism on Facebook. The uses and gratification theory in the context of social networking platforms undergirded this research in an attempt to discover if users consciously frame communications to emote certain responses and feedback from those in which they are connected through Facebook.

\section{Literature Review}

\section{Social Media Use}

Social media has ushered in a dynamic new way in which we communicate. The prevalence of letters, telephone calls, and face-to-face communication have been replaced by a new connectivity that spans the distant and creates endless options for communication with others via internetconnected computers or mobile phones (Drouin \& Miller, 2015). According to Duggan (2014) 91\% of adults in the United States own a cell phone and use it for a number of activities including sending or receiving text messages or accessing the internet, or gaming). Moreover, $73 \%$ of American adults engage in some type of social networking, and the list of popular social networking applications (e.g., Facebook, Twitter, Instagram, Pinterest, and LinkedIn) is ever-growing (Duggan \& Smith, 2014). Young adults seem particularly inclined to social networking: among this age group, a full $83 \%$ use social media (Duggan \& Brenner, 2013).

\section{Facebook}

Facebook is an online social networking website (with over 200 million active users) (Conroy, Feezell \& Geurrero, 2012). Once popular among 
younger generations and college students, Facebook has now become the platform for a new demographic. According to Nielsen (2012) the fastest growing group is the user between the ages of 35 and 54. As the platform has grown, so too have the features that allow users to do everything from post on other people's profiles, to sending notes, to now doing more than just 'liking' a post. Public figures can also create fan pages and profiles can be connected to other social media platforms. While the Facebook platform continues to evolve, the central focus of the social media site remains the same; to provide a platform for immediate and continued interact (Conroy, Feezell \& Geurrero, 2012).

\section{Uses and Gratification Theory}

Blumler and Katz's uses and gratification theory suggests that media users play an active role in choosing and using the media. Users take an active part in the communication process and are goal oriented in their media use. The theorists posit that users tend to seek out mediums that best meet their needs for attention, engagement and ease of use. Uses and gratifications assume that the user has alternate choices to satisfy their need (Griffin, 2000).

The uses and gratifications ( $U$ \& G) theory looks at media use from the human perspective; meaning that human needs drives the way individuals consume and use media. Theoretically, people can determine how they will use the media but cannot always determine how the media will affect them. Blumler and Katz (1974) validate the power of media users in that they present users as having the ability to choose media that will influence them in a particular manner and/or choose alternative forms of media that will deliver a desired influence. This theory presents an optimistic view of the media and does not legitimize the face that users can be unconsciously impacted by their own media consumption, thus negating the some of the noted power of the media in today's media entrenched environment (Griffin, 2000, pp 310, 364).

While research using $U \& \mathrm{G}$ theory has evolved since the 50s and 60s the aforementioned statement recognizing the failure of the theory to legitimize the power of the media continues to be a theoretical flaw (Ruggiero, 2000). Further, compartmentalization, an individualistic nature, varied definitions of gratification, the lack of clarity among some of the key concepts, and the reliance on the self-reporting of data make it difficult to deploy the theory or explain and predict to a more generalized population (Severin \& Tankard, 1997, p. 335). Critics of the theory also argue that any methodology that relies heavily on a self-reported interpretation of variables may not be valid (Rosenstein \& Grant, 1997). Studying the implications of media use is dependent on being able to make broader generalizations in correlations with the social and emotional impact of media consumption, thus reporting and interpreting data that reflect actual behavior is foundational. 


\section{Uses and Gratification Theory in a Social Media Environment}

The growth of the electronic media environment has been followed by a surge in empirical mass communication research; specifically research in the area of uses and gratification. Increased use of electronics raises new questions of media attendance. As the theory continues to develop, research has yielded its own classification scheme of audience functions; including shared gratification categories, different levels of gratification, gratification through various programs and sources. Additionally, the audience need is viewed as one that requires a range of content, serving various roles that are predetermined by the user (Matei, 2010).

According to LaRose and Eastin (2004), recent research about the Internet and Internet use has been extended and challenged as a means of trying to better understand media attendance by discovering a new sense of gratification and power as a result of the interaction the Internet offers. Studying $U$ \& $G$ theory as it relates to attention-seeking behavior is noteworthy because the media interactivity is essential to the notion that users engage in a mutually beneficial relationship built on control and exchanges. The discourse is controlled by the user who initiates the exchange (Williams, Rice, \& Rogers, 1988, p. 10). Research by Ha and James (1998) focuses on several dimensions of interactivity in the social media environment including:

1. playfulness

2. choice

3. connectedness

4. information collection

5. and reciprocal communication.

Dimensionally, users engage to fulfill a specific need. For example, playfulness is associated with web-surfers, those looking for connectedness are found to be more task-oriented than those users who are more expressive look for communication reciprocity.

\section{Facilitating Engagement Online}

Social networking sites are designed to facilitate engagement between online and offline friends, from sharing photos, to posting status updates, tweets, etc. People's motivation for using social networking sites varies from one platform to another (Emerson, 2011). For instance, with the advent of the selfie, Instagram has become the platform for self-promotion or status updates from a more visual perspective. Facebook users utilize the platform for more specific purposes including promotion of events, social action/activism, and inspiration to solicitation of support. In terms of facilitating engagement, interaction between family and friends ( $89 \%$ and $88 \%$, respectively) is the most documented reason why people use social media followed by finding new 
friends $(70 \%)$, products reviews (68\%), and entertainment $(67 \%)$ (Nielsen, 2012).

\section{Psychological Implications of Social Media Use}

From a psychological perspective, there is a lack of research which correlates the relationship between social media posting or usage and personality disorders or behavior. To address this, in 2012, a team of Norwegian researchers lead by Dr. Cecilie Andraessen published a psychological scale to measure Facebook addiction to research the link between behavior and Facebook use. The Bergen Facebook Addiction Scale (BFAS) started out with 18 items made up of three items for each of the six core elements of addiction: salience, mood modification, tolerance, withdrawal, conflict, and relapse. The scale was later finalized to six basic criteria:

1. You spend a lot of time thinking about Facebook or planning how to use it.

2. You feel an urge to use Facebook more and more.

3. You use Facebook in order to forget about personal problems.

4. You have tried to cut down on the use of Facebook without success.

5. You become restless or troubled if you are prohibited from using Facebook.

6. You use Facebook so much that it has had a negative impact on your job/studies.

The BFAS scale research found that psychological implications were greater among younger users. Additionally, the Norwegian team found that people with social insecurities were more likely to have greater social media dependency, individuals who were more goal-oriented had a lower tendency to become addicted to Facebook and women had the tendency to be more at risk of developing Facebook addiction. Critics of the BFAS note that the scale was most likely developed to investigate problematic use of Facebook however a new scale should be developed to address social networking as an activity rather than an aspect of a commercial product which Facebook is. Additionally, critics cite the need for clarity between addiction to the internet and addictions on the internet and a psychometrically validated tool that specifically accesses social networking addition (Paddock, 2015).

According to Lasala, Galigao \& Boquecosa (2013) there are positive psychological implications of social networking sites. Their research posits that a person's psychological well-being can be constructively influenced through a strong use of the social networking site. In addition, the study found an interaction between Facebook and psychological well-being measures. Social interaction in a social media environment is not constrained by societal norms (with the exception of behavior that can be interpreted as inappropriate or criminal that would be treated as such in the real world) thus the standard of behavior are virtually nonexistent. According to Lasala, et al, (2013) the more 
time spent by people in a virtual world, the more they develop confidence and a sense of psychological well-being driven by the id and the ego.

\section{Social Media Addiction}

Although Lasala et al. (2013) argue the positive effects of SNS, Haung and Leung (2009) have researched the damaging effect of a person's well-being in relation to social media use such as self-esteem and life satisfaction. Psychologists believe that it is important to identify where the emotional and mental attachment to social media comes from. There are five (5) specific types of social media use: meeting people, information seeking, distraction, coping and email. What opens the door to addiction is when people use social media primarily to reinforce relationships. Social media has become a significant means for peer-related communication and self-presentation. Facebook has become a social outlet for the user's social behavior. Not only has it become an outlet for motivated social behavior, but also Facebook activity is closely related to narcissism. Rauch (as cited in Whiteman, 2014) says that social media provides reinforcement every time a person logs on, thus leading to Facebook addition. Through word choice, users deploy a number of different tactics to regulate their self-esteem on social media through communication patterns. As needed, users will adjust the word choice in order to direct attention toward the desired outcome; meaning posts will be crafted to yield a desired emotional outcome or response (Buss \& Chiodo 1991). The goal of the narcissist is to gain admiration from followers by way of likes, mentions, or shares, however because the psychological underpinning of the need for affirmation is rooted in their psyche, the narcissist-user may not be aware of this implicit compensation process (DeWall, Buffardi, Bonser, and Campbell, 2011).

Individuals may also develop an addiction to the amount of likes, comments, reposts, and shares, which result from a given post. The power of the like indirectly pressures users to go to greater lengths to get noticed by friends and followers. Social media users crave feedback and responses (Seiter, 2014). Stephanie Tobin (nd) further investigates the addictive nature of social media in a study where half of the participants who regularly post to Facebook were told to function as active social media users and the other half of the participants were instructed to engage in 'lurking' or 'trolling' of followers who were active on Facebook. At the end of the study, those users who were in the non-posting group reported that they perceived their own self esteem to be adversely impacted by the lack of interaction.

The satisfaction one may get from the social media feedback triggers other actions as well. The fear of missing out is a large variable in Facebook addiction and self-seeking behavior. The fear of missing out (FOMO) which is an ancient phenomenon has seen a resurgence as a result of social media. Part of the human brain is wired to sense feelings of inclusion and this part of the limbic systems is designed to enable us to engage in protective actions (fight or flight, acknowledgment of threats or danger, etc.) to this end, the brain engages 
the same sort of reactions when one does not feel as if they are a part of an given social media 'in' group. While attention on Facebook or any other social media platforms is usually not a matter of life and death, for many people social media has become their community lifeline, thus the enactment of the "fight or flight" response and a feeling of being physiologically stressed if one is left out of the 'in group' on social media becomes a concern. This is further noted by in a discussion of repetitive checking behavior. Oftentimes users of social media will engage in this behavior not only to check the development and attention to their own posts but to ensure that they are not missing out on anything, which does not actually lessen their stress; this hypervigilant state just creates more stress (Sanz, 2015).

\section{Social Anxiety and Self-Worth}

Social Anxiety lies on a continuum between shyness and social phobias. Individuals may use the internet as a medium to regulate their social fears and related distress, particularly loneliness, depression, anxiety, and low selfesteem. The internet may well fulfill the social needs for some who have particular difficulty establishing social relationships, thus aiding social connectedness and providing a sense of belongingness. The internet creates a space in which social rejection can be alleviated; to a degree (Shepherd \& Edelmann, 2005).

Many Facebook users develop attachment anxiety, which ultimately leaves individuals sensitive about social feedback, leading them to engage in attention-seeking behavior on social media. Social media accounts tend to reflect individuals' characteristic cognitions; emotions and behavior in close relationships, as well as allow you to see the different ways of interacting with acquaintances and strangers. Self-esteem has also been examined as a measure for the amount and type of information that is disclosed on Facebook. According to Muise, Christofides and Desmarais (2009) the demand for popularity, trust, and self-esteem are closely associated with a user's social media interactions and behavior. Getting social feedback ultimately leads to a greater sense of belonging; however some of the negativity (by way of feedback and public scrutiny) can have a negative impact on relationships formed via social media.

\section{Validation Seeking and Self-Representation}

Significant research indicates that the need for affiliation and validation is powerful, fundamental, and with an extremely pervasive motivation for human beings. Research has also shown that maintaining positive relationships is an important factor for satisfaction in life. While there is limited research that investigates how users determine how they will seek out information what has been determined is the kinds of information that users desire. Cross, Rice and Parke (2001) outline in their research a grouping of five to information seeking benefits: 
- solutions

- meta-knowledge

- problem reformulation

- validation of plans or solutions,

- and legitimation.

In computer mediated environments where the user can not only selectively frame what is being communicated but can choose whom they are communicating with (a network of friends or groups) an understanding of the relational affective between users in the validation seeking process takes on greater implications when studying behavior in a SNS context.

Numerous studies have investigated the link between online selfrepresentation, self-esteem and narcissism. While the debate over using big data from social media research as a tool for understanding or explaining human behavior is ever present it is complimentary to the study of communication patterns, behaviors and beliefs in a social media context that have been the focus of other social science research (Nauert, 2014).

One of the most significant and psychological-based areas in terms of social media use is that of selective self-presentation. According to Walther (in Gonzales and Jeffery, 2010) the social media setting is designed to enable users to self-present in a way that is deemed important to self but also more socially acceptable and favorable to followers. Users purposefully select the way they present visual and written information. Computer-mediated communication (CMC) research also posits that users begin to embrace their own view of thy self, based on the way they have presented themselves in this asynchronous environment. This is referred to as identity shift; an occurrence in which these types of presentation have a strong correlation to the users concept of self (Gonzales \& Jeffery, 2010).

After a review of the literature, two research questions were posed:

1. Does social media post framing lead to self-seeking or narcissistic behavior?

2. What do Facebook users gain from strategically framed social media posts?

\section{Methodology}

This study was designed to explore Facebook usage and self-seeking behavior among users 25 and older. Participants $(n=140 ; 85 \%$ female and $15 \%$ male) for this study were drawn from a pool of applicants who voluntarily participated in this study. The questionnaire consisted of 6 demographic data collection questions and 26 questions designed to measure Facebook related behavior and activity including types of posts, image representation and motivation behind posts. Participants assessed Likert-type scale items deployed using online survey collection software. The student was presented as an investigation of social media usage. 


\section{Results and Discussion}

The results from this study support the existence of two different reasons behind why users are more prone to social media attention seeking behavior than others. Users either seek to find affirmation or use Facebook to maintain and foster relationships with people. Facebook reveals more about a person's intent than one may realize. One can quickly gain insight into a person's life by looking at their profile, thus users risk being judged differently from how they perceive themselves; as a mere user or a narcissist. Findings from this study suggest a relationship between socialization, engagement outside of social media and online behavior. Further, the findings indicate that attention seekers participate in behavior that engages individuals willing to provide empathy or respond to posts in a desired manner.

In terms of hours spent using Facebook, the majority of the respondents reported that they spend between 3 to 6 hours on the social media site.

With regard to empathy seeking posts, only $21 \%$ of the respondents reported that they post when they are feeling sad and a small percentage of respondents reported that they will follow up with a post related to personal sadness between 1 and 5 times a day.

In contrast to the finding about sad post, a significantly higher number of respondents reported that they post messages when they are feeling happy.

In a further analysis comparing sad versus happy posts, data revealed that participants seeking positive affirmation are more likely to construct posts that yield positive responses. One of the main tenets of the uses and gratification theory is that people seek out or use certain media to fulfill a specific need; thus users are conscious not only about the types of posts they create to elicit feelings (in this case responses to their happiness or sadness) but engage in non-scientific behavior of post monitoring to measure the success of their posts. In applying the theory of uses and gratification in a social media environment, one can come to better understand why users create certain posts and gain a better understanding of the level of sharing that goes on in the social media environment.

Roughly $21 \%$ of study participants reporting even posting sad messages once a week while almost $40 \%$ reported posting once a week when happy and another $31 \%$ reporting that they post messages when they are happy, two to three times a week. Gordon (2014) posits that excessive attention seeking evolves over time and that individuals become wired to equate the lack of attention to negative feedback. The way that individuals are able to counter these feelings through social media is to frame their social media engagement in such a way as to yield the responses that he or she desires.

Posting of images is another way that social media users seek satisfaction and interaction, thus the self-portrait has become a significant part of many social media platforms. The selfie phenomenon suggests (from a semantic perspective) that one is engaging in the act of self-generated attention or affection-generating from a photo. 
Table 1. Hours spent on Facebook

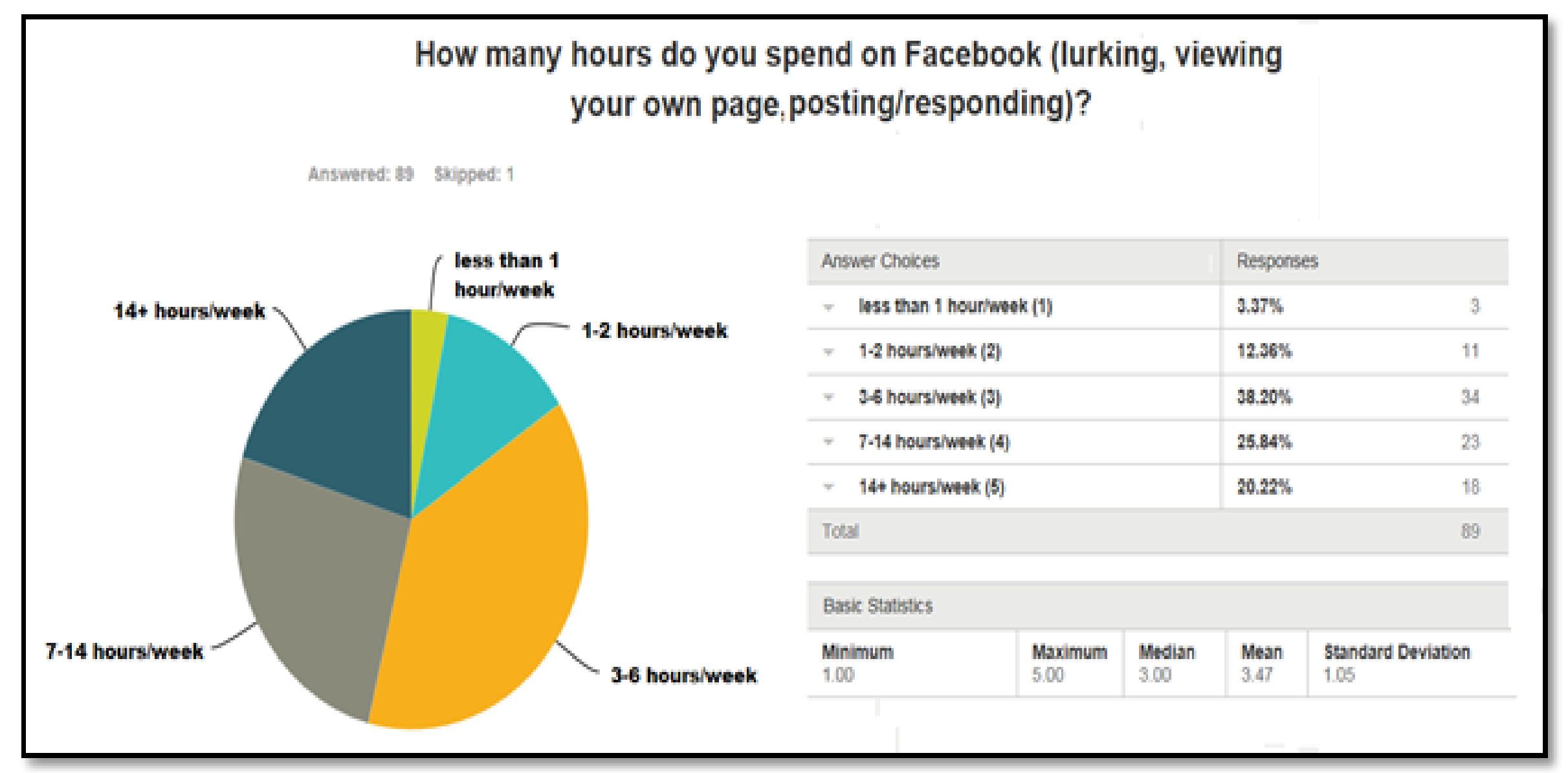


Table 2. Posting when feeling sad

\begin{tabular}{|c|c|c|c|c|c|}
\hline \multicolumn{6}{|c|}{$\begin{array}{r}\text { How often do you post messa } \\
\text { you're feeling sad? }\end{array}$} \\
\hline \multicolumn{4}{|c|}{ Answered: 90 Skipped: 0} & \multicolumn{2}{|c|}{ Responses } \\
\hline \multicolumn{4}{|c|}{ never (1) } & $74.44 \%$ & 67 \\
\hline \multicolumn{4}{|c|}{ once a week (2) } & $21.11 \%$ & 19 \\
\hline \multicolumn{4}{|c|}{2 to 3 times a week ( 3 ) } & $4.44 \%$ & 4 \\
\hline \multicolumn{4}{|c|}{ more than 5 times a week (4) } & $0.00 \%$ & 0 \\
\hline \multicolumn{5}{|l|}{ Total } & 90 \\
\hline \multicolumn{6}{|c|}{ Basic Statistics } \\
\hline \multicolumn{2}{|l|}{$\begin{array}{l}\text { Minimum } \\
1.00\end{array}$} & $\begin{array}{l}\text { Median } \\
1.00\end{array}$ & $\begin{array}{l}\text { Mean } \\
1.30\end{array}$ & \multicolumn{2}{|c|}{$\begin{array}{l}\text { Standard Deviation } \\
0.55\end{array}$} \\
\hline
\end{tabular}


Table 3. Post monitoring (sad)

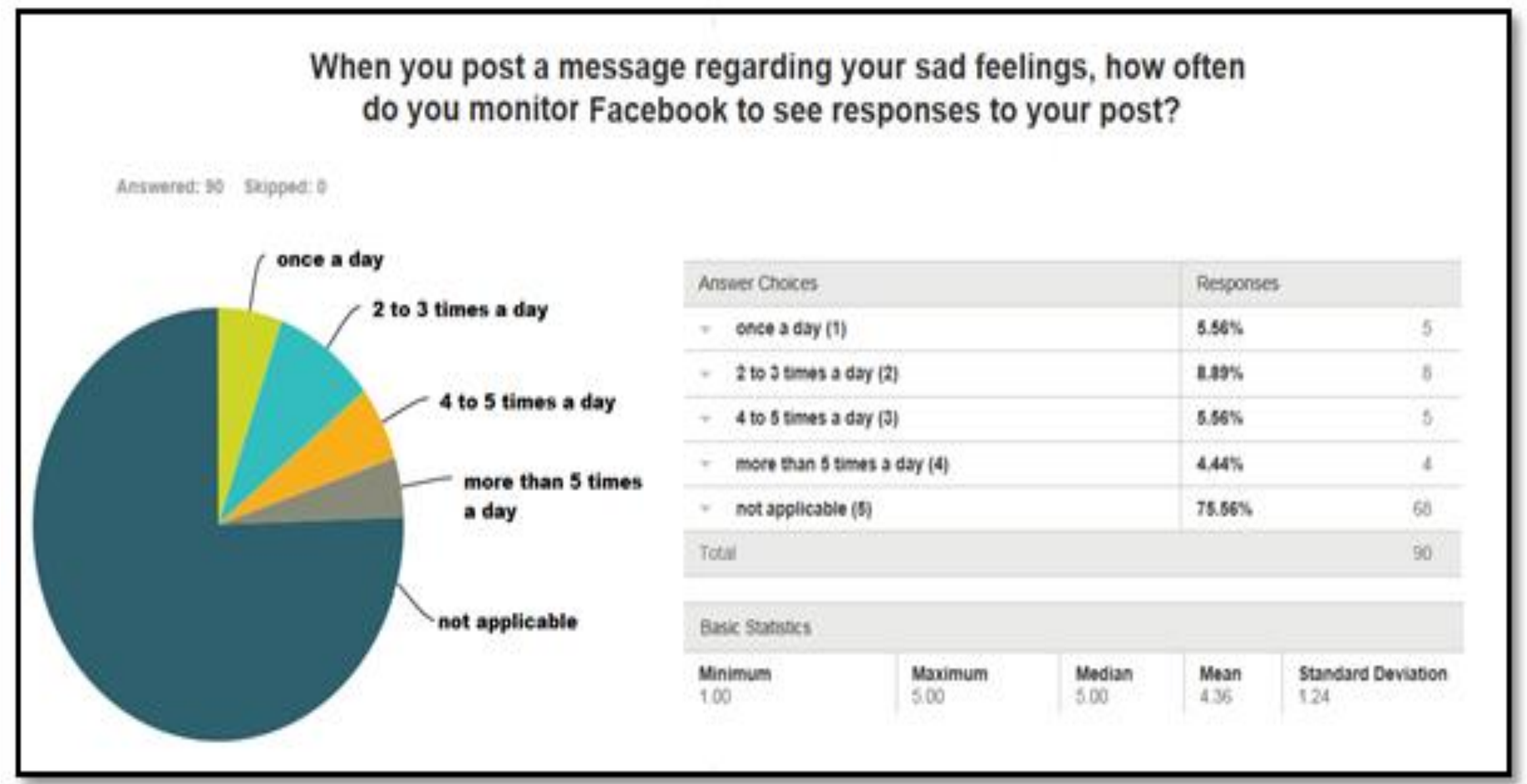


Table 4. Posting when feeling happy

\begin{tabular}{|c|c|c|c|c|c|}
\hline \multicolumn{6}{|c|}{$\begin{array}{l}\text { How often do you post mes } \\
\text { you're feeling happ } \\
\text { Answered: } 90 \text { Skipped: } 0\end{array}$} \\
\hline \multicolumn{4}{|c|}{ Answer Choices } & \multicolumn{2}{|c|}{ Responses } \\
\hline \multicolumn{4}{|c|}{ never (1) } & $14.44 \%$ & 13 \\
\hline \multicolumn{4}{|c|}{ once a week (2) } & $38.89 \%$ & 35 \\
\hline \multicolumn{4}{|c|}{2 to 3 times a week ( 3 ) } & $31.11 \%$ & 28 \\
\hline \multicolumn{4}{|c|}{ more than 5 times a week (4) } & $15.56 \%$ & 14 \\
\hline \multicolumn{5}{|l|}{ Total } & 90 \\
\hline \multicolumn{6}{|c|}{ Basic Statistics } \\
\hline \multicolumn{2}{|l|}{$\begin{array}{l}\text { Minimum } \\
1,00\end{array}$} & $\begin{array}{l}\text { Median } \\
2.00\end{array}$ & $\begin{array}{l}\text { Mean } \\
2.48\end{array}$ & \multicolumn{2}{|c|}{$\begin{array}{l}\text { Standard Deviation } \\
0.92\end{array}$} \\
\hline
\end{tabular}


Table 5. Post monitoring (happy)

\begin{tabular}{|c|c|c|c|c|c|c|c|}
\hline \multirow{10}{*}{$\begin{array}{l}\text { more than } 5 \\
\text { times a day }\end{array}$} & \multicolumn{7}{|c|}{$\begin{array}{l}\text { When you post a message regarding your happy feelings, how often } \\
\text { do you monitor Facebook to see responses to your post? }\end{array}$} \\
\hline & day & \multicolumn{4}{|c|}{ Answer Chokes } & Responses & \\
\hline & & \multicolumn{4}{|c|}{ - once a day (1) } & $21.59 \%$ & 19 \\
\hline & & \multicolumn{4}{|c|}{2 to 7 times a day (2) } & $30.68 \%$ & 27 \\
\hline & & \multicolumn{4}{|c|}{4005 times a day (3) } & $10.22 \%$ & 9 \\
\hline & & \multicolumn{4}{|c|}{ more than 5 times a day (6) } & $21.5 \%$ & ns \\
\hline & & \multicolumn{4}{|c|}{ not applicable (5) } & $16.91 \%$ & 14 \\
\hline & & \multicolumn{5}{|l|}{ Total } & 88 \\
\hline & & \multicolumn{6}{|c|}{ Basik Suturstes } \\
\hline & 2 to 3 times a day & $\begin{array}{l}\text { Minimum } \\
1.00\end{array}$ & $\begin{array}{l}\text { Maximum } \\
5.00\end{array}$ & $\begin{array}{l}\text { Median } \\
2.00\end{array}$ & $\begin{array}{l}\text { Mesn } \\
2.80\end{array}$ & \multicolumn{2}{|l|}{$\begin{array}{l}\text { Standard Deviaben } \\
1.41\end{array}$} \\
\hline
\end{tabular}


There is a large degree of intentionality when it comes to the posting of images of thy self and are self-selected and interpreted to have a role and meaning that we understand about ourselves and want others to understand. We look for meaning in our selfies, whether the pictures are silly, reflective, selective (showing a particular body part or angel, etc.). Selfies communicate a transitory message and in most instances the individual posting is more concerned with the context rather than the projection of identity (Gonzales and Jeffery 2010); however the added value of filters, graphics, and applications designed to Photoshop ${ }^{\circledR}$ or edit photos may suggest otherwise, in that some users invest time in filtering their own images before posting while others will make a statement about their 'self' by captioning whether a photo has been altered, thus eluding to a subconscious message about the authenticity of self or others in the social media domain. According to Table 6, the data revealed that while $59 \%$ of the respondents reported never posting a selfie the responses from $41 \%$ of the respondents who have or do post images of themselves does support a desire to see if posts of selfies are getting views.

In contrast to a study conducted by Carpenter (as referenced Bergland, 2013) in which Carpenter studies self-promoting behavior, the entitlement/ exploitativeness and exhibitionistic tendencies of Facebook users, data revealed that participants used Facebook less to repair damaged egos or seek social support, rather using the platform to engage in pro-social activities with individuals considered friends or family.

While the data revealed little about fear of missing out (FOMO) in the context of the overall use of social media, what is revealed is that the posting monitoring behavior exhibited by users is directly related to the post framing in that certain responses are expected as a result of the post. While it is not apparent in the research that the participants exhibited any traits of FOMO, what is exhibited is a user's need for response-based social interaction which causes them to engage in a behavior that is similar to that which is displayed in terms of FOMO and social media, or the addictive nature of staying connected that causes users to chronically check social media sites or posts.

One factor that distinguishes the research participants in this study apart from participants in the larger body of research on social media usage and behavior is the target demographic. Participants in this study were not children or millennial users; rather respondents between the ages of 30 and 40 . The social media behavior of this demographic is very intentional which has direct implications for those developing social media sites, for businesses or organizations who advertise or market social media platforms, and for the users who seeks to prompt a certain response when using social media. 
Table 6. Selfie posting

\begin{tabular}{|c|c|c|c|c|c|}
\hline \multirow{2}{*}{\multicolumn{6}{|c|}{$\begin{array}{c}\text { When you post a 'selfie', r } \\
\text { monitor Facebook to see r } \\
\text { post? }\end{array}$}} \\
\hline & & & & & \\
\hline \multicolumn{4}{|c|}{ Answer Choices } & \multicolumn{2}{|c|}{ Responses } \\
\hline \multicolumn{4}{|c|}{ once a day (1) } & $10.11 \%$ & 9 \\
\hline \multicolumn{4}{|c|}{$\quad 2$ to 3 times a day (2) } & $14.61 \%$ & 13 \\
\hline \multicolumn{4}{|c|}{4 to 5 times a day (3) } & $6.74 \%$ & 6 \\
\hline \multicolumn{4}{|c|}{ more than 5 times a day (4) } & $7.87 \%$ & 7 \\
\hline \multicolumn{4}{|c|}{ not applicable (5) } & $60.67 \%$ & 54 \\
\hline \multicolumn{5}{|l|}{ Total } & 89 \\
\hline \multicolumn{6}{|c|}{ Basic Statistics } \\
\hline \multicolumn{2}{|l|}{$\underset{1.00}{\text { Minimum }}$} & $\begin{array}{l}\text { Median } \\
5.00\end{array}$ & $\begin{array}{l}\text { Mean } \\
3.94\end{array}$ & $\begin{array}{l}\text { Standa } \\
1.47\end{array}$ & \\
\hline
\end{tabular}


The data provided insight into how participants utilize social media, cultivate relationships for the expressed purpose of gratification seeking and affirmation and how they negotiate the space of social media when their content or self-views are not viewed or responded to as desired.

In addition to this insight, patterns of exaggerated opinion framing were also revealed. These patterns highlight the fact that on social media individuals will engage in arguments over social or controversial issues. Facebook has become an environment where public opinion is constructed, thus providing a space for individuals to discuss current and controversial events. Respondents $(n=46 \%$ reported that they have engaged in a debate or heated argument on Facebook with $48 \%$ reporting that they have unfriended someone because of toxicity in response to a post. According to Waldman (nd) the emotional fallout as enacted over social network is not associated with a high costs as unfriending often is done to preserve one's own mental health and that the unfriender nor the unfriended risk the likelihood of suffering as the cost of maintaining online friendships is relatively low. These patterns of exaggerated framing and unfriending provide a fertile ground for new and extended research in social media.

\section{Limitations}

There were limitations to the current study. First, the pool of respondents was limited to the researchers Facebook pool of friends with an expectation that sharing the post would yield more respondents. Another limitation was that the data were collected as self-reported responses on a survey. Therefore, there may be a disparity between what the participants see about themselves and what was actually true. In a future study, participations may be asked to participate in a second phase of the study by consenting to have their online activity observed. Research in the area of social media use and self-seeking behavior will continue as platforms are expanded and new ones are introduced and as the debate about self-esteem and online behavior grows. While there is a limited amount of research on this topic and with respect to the demographic of Facebook users selected for this study the field of media psychology as an emergent field can combine an understanding of human behavior, cognition and emotional behavior in the social media environment. This crossdisciplinary framework may not only help to give research attention to media use and development but it may become necessary as media technologies are growing at an exponential rate.

\section{Conclusion}

As users of social media, there may be the inclination to believe that users are able to mask insecurities or portray themselves in the most favorable light, 
however, behavior on social media reveals more than users might think. It is not just what is posted on Facebook that reveals information about an individual's personality - it is also what is not posted that can be quite telling. Based on the survey data collected, there is a correlation between social media post framing and a tendency towards narcissistic behavior as a significant number of participants reported monitoring of post that revealed specific emotional detail about the poster. According to Gordon (2014) excessive attention seeking is not a character flaw. He asserts that attentionseeking in terms of brain function, cannot be fixed, but it can be managed. Adult behavior which is primarily intended to elicit attention in the social media environment can often redirected when the individual is denied the attention they seek. To this end, the research also revealed that social media framing does provide a direct benefit to the user in that they can create a post that will elicit a thread of responses that fall in line with their perceived response outcome to the respective post. Further, when those perceived responses are not delivered the user has the ability to block users, reframe, repost, or delete the post altogether.

Future research can look at areas of blocking, reframing and post deletion and what may cause a user to engage in these behaviors. More in-depth research that studies the psychological implication of social media by adult users is also significant to the body of work as much of the research looks at the psychological implications of millennial or younger users. Research in this field should continue to grow as the demand or use of social media platforms will continue to grow and new platforms will be introduced. Researchers should also look at more specific forms of online engagement and how understanding this engagement can lead to an expanded understanding social media use.

\section{References}

Bergland, C. (2013). Social media's dual-edge sword: Narcissism vs. self-esteem. Retrieved from https://www.psychologytoday.com/blog/the-athletes-way/201306/ social-media-s-dual-edged-sword-narcissism-vs-self-esteem.

boyd, D. M., \& Ellison, N. B. (2008). Social network sites: Definition, history, and scholarship. Journal of Computer-Mediated Communication, 13, 210-230.

Blumler J.G. \& Katz, E. (1974). The uses of mass communications: Current perspectives on gratifications research. Beverly Hills, CA: Sage.

Buss, D.M. \& Chiodo, L. M. (1991) Narcissistic acts in everyday life. Journal of Personality, 59, 179-215.

Conroy, M., Feezell, J., \& Geurrero, M. (2012). Facebook and political engagement: A study of online political group membership and offline political engagement. Computers in Human Behavior, 28, 1535-1546.

Cross, R. Rice, R. E. \& Parke, A. (2001). Information seeking in social context: Structural influences and receipt of information benefits. IEEE Transactions on Systems, Man, and Cybernetics- Part C: Applications and Reviews. 31, 4, 438448.

Dewall, C.N. Buffardi, L.E., Bonser, I. \& Campbell, W.K. (2011). Narcissism and 
implicit attention seeking: Evidence from linguistic analyses of social networking and online presentation. Personality and Individual Differences, 51: 57-62.

Drouin, M. and Miller, D.A. (2015). Why do people record and post illegal material? Excessive social media use, psychological disorder, or both? Computers in Human Behavior. 48: 608-614.

Duggan, M. (2014). Cell phone activities 2013. Pew Internet Research. http://www.pe winternet.org/files/oldmedia//Files/Reports/2013/PIP_Cell\%20Phone\%20Activiti es\%20May\%202013.pdf>.

Duggan, M. \& Brenner, J. (2013). The demographics of social media users - 2012. Pew Internet \& American Life Project, http:pewinternet.org/ /media/Files/Re ports/2013?PIP_SocialMediaUsers.pdf $>$.

Duggan, M., \& Smith, A. (2014). Social media update 2013. Pew Internet Research. http:www.pewinternet.org/Reports/2013/Social-Media-Update.aspx>.

Emerson, R. (2011). New study probes how we use social media. Retrieved from: http://www.huffingtonpost.com/2011/09/28/social-media-study_n_985102.html

Freberg, K., Adams, R., McGaughey, K. \& Freberg, L. (2010) The rich get richer: Online and offline social connectivity predicts subjective loneliness. Media Psychology Review. Vol. 3(1). Retrieved from: http://mprcenter.org/review/fre bergonline-connectivity/

Gonzales, A. L. \& Jeffery, M.A. (2010). Mirror on my Facebook wall: Effects of exposure to Facebook on self-esteem. Cyberpsychology, Behavior, And Social Networking Volume 00, 1-5.

Gordon, B. (2014). Excessive attention seeking and drama addiction: Portrait of neglect. Retrieved from https://www.psychologytoday.com/blog/obesely-spea king/201411/excessive-attention-seeking-and-drama-addiction

Griffin, E. (2000). A first look at communication theory (4th ed.). Massachusetts: McGraw-Hill. P 310, 364.

Ha, L., \& James, E. L. (1998). Interactivity reexamined: A baseline analysis of early business websites. Journal of Broadcasting \& Electronic Media, 42, 457-474.

Haung, H., \& Leung L. (2009) Instant messaging addiction among teenagers in China: Shyness, alienation, and academic performance decrement. CyberPsychology \& Behavior, 12(6), 675-679.

Kraut, P., M., P., Lundmark, V., Kiesler, S., Mukopadhyay, T., \& Scherlis, W. (1998). Internet paradox: A social technology that reduces social involvement and psychological well-being? American Psychologist, 53, 65-77.

Lasala,C.B., Galigao, R.P. and Boquecosa, J.F. (2013). Psychological impact of Social Networking Sites: A Psychological Theory. UV Journal of Research. 82-86.

LaRose, R. \& Eastin, M.S. (2004). A Social cognitive theory of internet Uses and Gratifications: Toward a new model of media attendance. Journal of Broadcasting \& Electronic Media, 48(3), pp 358-377.

Matei, S, A. (2010). What can uses and gratifications theory tell us about social media? Retrieved from: http://matei.org/ithink/2010/07/29/what-can-uses-andgratifications-theory-tell-us-about-social-media/.

Muise, A., Christofides, E., \& Desmarais, S. (2009). More Information than You Ever Wanted: Does Facebook Bring Out the Green-Eyed Monster of Jealousy? Cyber Psychology \& Behavior, 12: 441-444.

Nauert. R. (2014). Using social media as a new tool to explain human behavior. Retrieved from: http://psychcentral.com/news/2014/02/14/using-social-media-asnew-tool-to-explain-human-behavior/65880.html. 
Nielsen. (2012). State of the media: The social media report. Retrieved from: http:// www.nielsen.com/us/en/insights/reports/2012/state-of-the-media-the-social-medi a-report-2012.html

Paddock, C. (2015). Facebook addiction: New psychological scale. Medical News Today. Retrieved from: http://www.medicalnewstoday.com/articles/245251.php

Rosenstein, A. W., \& Grant, A. E. (1997). Reconceptualizing the role of habit: A new model of television audience. Journal of Broadcasting \& Electronic Media, 41, 324-344.

Ruggiero, T. E. (2000). Uses and Gratifications theory in the $21^{\text {st }}$ century. Mass Communications in Society. 3(1), 3-37.

Rutledge, P. (nd). What is media Psychology? Retrieved from: http://mprcenter.org/ what-we-do/what-is-media-psychology/.

Sanz, A. (2015). What's the psychology behind the fear of missing out? Retrieved from:http://www.slate.com/blogs/quora/2015/09/30/fomo_what_s_the_psycholog y_behind_the_fear_of_missing_out.html.

Seiter, C. "7 Social media psychology studies that'll make your marketing smarter." Buffer Social. 13 Aug. 2014. Web. 18 Nov. 2015.

Severin W. J., \& Tankard, J. W. (1997). Uses of Mass Media. In W. J. Severin, \& J. W. Tankard (Eds.) Communication Theories: Origins, Methods, and Uses in the Mass Media (4th ed.). New York: Longman.

Shepherd, R. \& Edelmann, R. (2005). Reasons for internet use and social anxiety. Personality and Individual Differences. 39(5), 949-958.

Tsao, J. (1996). Compensatory media use: An exploration of two paradigms. Communication Studies, 47, 89-199.

Tobin, S. (nd). Psychology of social networks: what makes us so addicted? Retrieved from: http://www.keepitusable.com/blog/?p=2568.

Waldman, K. (nd). The Psychology of Unfriending Someone on Facebook. Retrieved from:http://www.slate.com/blogs/future_tense/2014/04/24/the_psychology_of_un friending_someone_on_facebook.html.

Whiteman, H. (2014) social media: How does it affect our mental health and wellbeing? Medical News Today. Retrieved from: http://www.medicalnewstoday. com/articles/275361.php

Williams, F., Rice, R. E., \& Rogers, E. M. (1988). Research methods and the new media. New York: Free Press. 